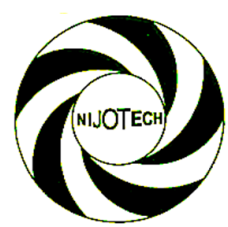

Nigerian Journal of Technology (NIJOTECH)

Vol. 34 No. 3, July 2015, pp. 438 - 442

Copyright(C) Faculty of Engineering,

University of Nigeria, Nsukka, ISSN: 0331-8443

www.nijotech.com

http://dx.doi.org/10.4314/njt.v34i3.2

\title{
SUBJECTIVE APPROACH TO HUMAN PHYSIOLOGICAL RESPONSES TO OUTDOOR CONDITION DURING BLOCKLAYING IN OGUN STATE, NIGERIA
}

\author{
A. I. Musa*,1, S. 0. Ismaila2, M. A. Waheed ${ }^{3}$ and T. M. A. Olayanju ${ }^{4}$

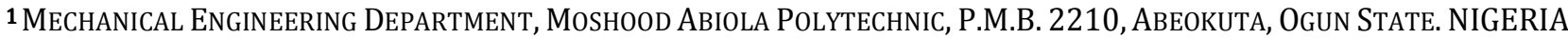

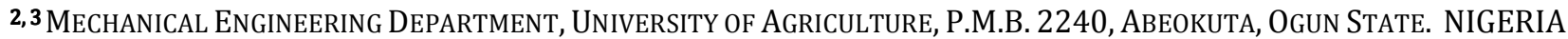

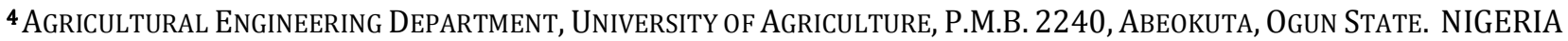 \\ Email addresses: ${ }^{1}$ kunlemusa@yahoo.com; 2 ismailasalami@yahoo.com;3 akindoye@gmail.com; \\ 4 tiyanju@gmail.com
}

\begin{abstract}
This study was based on the subjective responses of the masons that are performing physical activity of blocklaying in the outdoor condition in Ogun State Nigeria. A total of 204 masons were investigated on the average of seventeen (17) masons monthly. The subjective responses were recorded from May, 2013 to April, 2014. The data collected were analysed with SPSS 17 version. The mean air temperature was at maximum in November $2013\left(36.1^{\circ} \mathrm{C}\right)$ and March 2014 (36.1 ${ }^{\circ} \mathrm{C}$ ) and maximum relative humidity also occurred in July 2013 (69\%). Similarly, the radiant temperature was at maximum in June $2013\left(36.9^{\circ} \mathrm{C}\right)$ and the peak value of the solar radiation occured in December $2013\left(806 \mathrm{w} / \mathrm{m}^{2}\right)$. In addition, the maximum average mean skin temperature of the mason occurred in March 2014 $\left(34.8^{\circ} \mathrm{C}\right)$ and the core temperature in September $2013\left(35.2^{\circ} \mathrm{C}\right)$. Questionnaires were administered on two thousand and forty $(2,040)$ masons to obtain necessary information on the subjective responses. The masons were interviewed every hour to capture the thermal behaviour of the environment while performing their activities. The study revealed that 76.50, 76.65, 88.30 and $76.3 \%$ were thermally comfortable with the environmental conditions in June 2013, February, March and April 2014 respectively. This could affect the performance output which is a subject of the effectiveness.
\end{abstract}

\section{Keywords: Human, Mason, Comfort, Physiological, Subjective, Environmental, Outdoor.}

\section{INTRODUCTION}

In an outdoor environment, skin temperature of the mason is a very difficult task to detect due to the temperature variation of the skin. According to Bulcao et al [1] and Yao et al [2] stated that thermal comfort is largely determined by the skin temperature with respect to physiological responses which are linked to the core temperature. The comfort assessment in outdoor environment entails typical six parameters that cannot be overemphasized. The parameters include four outdoor climatic conditions and two that are related to the human behaviour. The interaction between all the climatic parameters of air temperature, radiant temperature, wind speed and relative humidity determined the human physiological responses to the outdoor conditions [3]. The two parameters that relate human being are the metabolic activity and the type of clothing. For a given metabolic activity, the skin temperature and sweat production rate are seen to be the only physiological variables that influence the heat balance [4].

Yao et al [2] suggested the use of thermal acceptability approach on human physiology and this focuses on the skin temperature which is the primary parameter to the human comfort. The subjective rating for thermal sensation according to Fanger [5] that is common is the 7 -point scale $(+3=$ hot, $0=$ neutral and $-3=$ cold $)$. Maw et al [6] and Sparks et al [7] reported that subjective response is affected by the climatic condition of the environment and the physiological also affect the metabolic rates [8].

Nikolopoulou et al [9] conducted a research on the thermal comfort condition of urban open space as resting area in Cambridge. The research assessed people through interview of their subjective response to the thermal sensation on a 5-point scale varying from the "too cold to too hot". The authors also considered the environmental characteristic such as air temperature, relative humidity, solar radiation, radiant temperature and wind speed with their individual characteristic such as age, sex, clothing etc.

Thorsson et al [10] also conducted a research on the subjective outdoor thermal comfort and human activity in an urban environment that is much densely built up like North American cases. The author used a 9-point scale to evaluate the subjective thermal sensation of 1192 individuals through the use of questionnaires. The study was compared with Nikolopoulou et al [9] and the physiological equivalent temperature curve was skewed towards the warm zone. The studies 
discussed above were all conducted where a warm condition and sunlight are positive factors that affect the use of outdoor environment among the people. Parsons [11] suggested that one of the methods to determine what people feel is to use a subjective questionnaire. Not only thermal sensation, comfort, pleasure but also behavioural effects are induced by all psychological phenomena.

\section{MATERIALS AND METHODS}

Two hundred and four (204) masons performing blocklaying in outdoor environment were randomly selected from different locations in Ogun State, Nigeria for investigation. The study was conducted between $8.00 \mathrm{am}$ and $5.00 \mathrm{pm}$ from May 2013 to April 2014 at latitude of $7^{0} .00 \mathrm{~N}$ and a longitude of $03^{0} .31^{1} \mathrm{E}$ (Ogun State Nigeria) and covered the rain and dry seasons. The masons' thermal environments were assessed by measuring the environmental and physiological parameters as well as using the thermal indices. The description of the environmental parameters includes the values of air temperature, wind speed, relative humidity, radiant temperature and solar radiation. Metabolic heat production (activity) and clothing insulation were also noted in the analysis of heat transfer between the body and the environment.

Environmental conditions were recorded around the masons. The air temperature was recorded using GM013-Thermo-Hygro digital thermometerHygrometer with external sensor (Shenzhen Kai Heng Jie Technology Ltd, China) and the radiant temperature was also recorded with infrared thermometer pointed to the blackbody. Solar radiation was also measured using solar power meter SM 206 (Shenzhen Sanpo Instrument Co. Ltd, China) with resolution of $0.1 \mathrm{~W} / \mathrm{m}^{2}$, $0.1 \mathrm{Btu} / \mathrm{ft}^{2} \mathrm{~h}$ while the wind speed was measured using vane probe Anemometer, Am-4201 microprocessor digital anemometer (Lutron Electronics Enterprise co Ltd, Taiwan).

The physiology of human thermo-regulation involves the measurement of body (core) temperature and skin temperature because human body responds to thermal conditions through physiological system of thermo- regulation. The Masons were weighed every two hours using Detecto PD300MDHR column scale (Cardinal Scale manufacturing company, USA) with digital height to measure body mass $(\mathrm{kg})$ and height $(\mathrm{cm})$ simultaneously. The skin temperature was measured using infrared Smart sensor AR8720 thermometer (Shenzhen Kai Heng Jie Technology Ltd, China) number 00505613 with thermometric range of $-50^{\circ} \mathrm{C}$ to $1050^{\circ} \mathrm{C}$ pointing to the forehead of the subject at $1.2 \mathrm{~m}$ distance while Oral temperature was measured before every two hours using a Dx-101 water resistant digital clinical thermometer (Hicks thermometer Ltd, Indian). The questionnaire about subjective responses consists of thermal sensation, thermal comfort, preference, pleasantness, acceptance and satisfaction. In the case of thermal sensation, the 11-point scale from extremely hot to extremely cold was used. Thermal comfort consists of 4-point scales, ranging from not uncomfortable to very uncomfortable. In terms of preference and pleasantness, 7 points from much cooler to much warmer and from very unpleasant to very pleasant was used. Acceptance and satisfaction was divided into two points of acceptable and unacceptable and satisfied and dissatisfied.

Two thousand and forty $(2,040)$ questionnaires were administered to 204 masons every hour in the study. The questionnaire consists of thermal sensation, comfort, preference, pleasantness, acceptance and satisfaction. 11-point scale of the thermal sensation and the comfort was used from extremely hot to extremely cold.

The data collected were analysed statistically with SPSS version 17 [12] and Microsoft Excel (2010) [13]. software.

\section{RESULTS}

Tables 1 to 8 show the average mean values of the environmental parameters, the physiological parameters and subjective responses which are needed for the actual prediction of human working in outdoor environment.

Table 1: Average Mean Values of the Environmental Parameters

\begin{tabular}{lllllllllllll}
\hline Parameter & May & \multirow{2}{*}{ Jun '13 } & \multirow{2}{*}{ Jul'13 } & \multirow{2}{*}{ Aug '13 } & \multirow{2}{*}{ Sep '13 } & \multirow{2}{*}{ Oct'13 } & \multirow{2}{*}{ Nov'13 } & \multirow{2}{*}{ Dec '13 } & \multirow{2}{*}{ Jan '14 } & \multirow{2}{*}{ Feb '14 } & \multirow{2}{*}{ Mar'14 } & \multirow{2}{*}{ Apr'14 } \\
\hline Air Temp & 31.6 & 33.3 & 27.9 & 30.5 & 33.1 & 32.8 & 36.1 & 32.8 & 34.2 & 35.0 & 36.1 & 34.4 \\
R H & 58 & 58 & 69 & 56 & 55 & 56 & 58 & 53 & 57 & 42 & 54 & 48 \\
Wind Speed & 0.5 & 0.4 & 0.5 & 0.4 & 0.5 & 0.5 & 0.5 & 0.5 & 0.5 & 0.5 & 0.5 & 0.5 \\
Solar Radiation & 571 & 583 & 551 & 779 & 668 & 771 & 725 & 806 & 648 & 484 & 706 & 660 \\
Radiant Temp & 34.6 & 36.9 & 29.5 & 31.6 & 33.9 & 32.5 & 33.4 & 32.9 & 35.6 & 35.6 & 35.8 & 35.6 \\
\hline
\end{tabular}

Table 2: Average Mean Values of the Physiological Parameters

\begin{tabular}{ccccccccccccc}
\hline Parameter & $\begin{array}{c}\text { May } \\
\text { '13 }\end{array}$ & Jun '13 & Jul'13 & $\begin{array}{c}\text { Aug } \\
\text { '13 }\end{array}$ & Sep '13 & Oct'13 & $\begin{array}{c}\text { Nov } \\
\text { '13 }\end{array}$ & $\begin{array}{c}\text { Dec } \\
\text { '13 }\end{array}$ & $\begin{array}{c}\text { Jan } \\
\text { '14 }\end{array}$ & Feb '14 & Mar'14 & Apr'14 \\
\hline Height $(\mathrm{cm})$ & 170.0 & 170.0 & 168.0 & 166.2 & 166.7 & 168.3 & 166.8 & 165.9 & 171.7 & 168.2 & 169.4 & 168.6 \\
Body Mass $(\mathrm{kg})$ & 63.4 & 60.7 & 64.1 & 62.9 & 62.8 & 61.2 & 61.2 & 62.5 & 62.6 & 64.1 & 63.0 & 63.3 \\
Skin Temp $\left({ }^{\circ} \mathrm{C}\right)$ & 33.1 & 33.2 & 34.4 & 33.5 & 34.0 & 33.9 & 33.9 & 34.1 & 34.3 & 34.5 & 34.8 & 34.6 \\
Core Temp $\left({ }^{\circ} \mathrm{C}\right)$ & 35.0 & 34.8 & 34.3 & 33.4 & 35.2 & 34.5 & 34.8 & 34.4 & 33.2 & 33.5 & 33.3 & 33.1 \\
\hline
\end{tabular}


Table 3: Subjective measurement of thermal sensation

\begin{tabular}{|c|c|c|c|c|c|c|c|c|c|c|c|c|c|c|c|c|c|c|c|c|c|c|c|c|}
\hline & \multicolumn{2}{|c|}{ MAY'13 } & \multicolumn{2}{|c|}{ JUN'13 } & \multicolumn{2}{|c|}{ JUL'13 } & \multicolumn{2}{|c|}{ AUG'13 } & \multicolumn{2}{|c|}{ SEPT'13 } & \multicolumn{2}{|c|}{ OCT'13 } & \multicolumn{2}{|c|}{ NOV'13 } & \multicolumn{2}{|c|}{ DEC'13 } & \multicolumn{2}{|c|}{ JAN'14 } & \multicolumn{2}{|c|}{ FEB'14 } & \multicolumn{2}{|c|}{ MAR'14 } & \multicolumn{2}{|c|}{ APR'14 } \\
\hline & $\mathrm{N}$ & $\%$ & $\mathrm{~N}$ & $\%$ & $\mathrm{~N}$ & $\%$ & $\mathrm{~N}$ & $\%$ & $\mathrm{~N}$ & $\%$ & $\mathrm{~N}$ & $\%$ & $\mathrm{~N}$ & $\%$ & $\mathrm{~N}$ & $\%$ & $\mathrm{~N}$ & $\%$ & $\mathrm{~N}$ & $\%$ & $\mathrm{~N}$ & $\%$ & $\mathrm{~N}$ & $\%$ \\
\hline Extremely Hot & - & & - & & - & & - & & - & & - & & - & & - & & - & & - & & - & & - & \\
\hline Very Hot & - & & - & & - & & - & & - & & - & & - & & - & & - & & 2 & 11.8 & 4 & 23.5 & 3 & 17.7 \\
\hline Hot & - & & - & & - & & - & & 2 & 11.8 & 7 & 41.2 & 2 & 11.8 & 3 & 17.7 & 5 & 29.4 & 4 & 23.5 & 6 & 35.3 & 6 & 35.3 \\
\hline Warm & 6 & 35.3 & 8 & 47.1 & 4 & 23.5 & 2 & 11.8 & 6 & 35.3 & 6 & 35.3 & 8 & 47.1 & 7 & 41.2 & 8 & 47.1 & 6 & 35.3 & 3 & 17.7 & 4 & 23.5 \\
\hline Slight warm & 7 & 41.2 & 3 & 17.7 & 6 & 35.3 & 6 & 35.3 & 3 & 17.7 & 3 & 17.7 & 4 & 23.5 & 6 & 35.3 & 4 & 23.5 & 5 & 29.4 & 2 & 11.8 & 2 & 11.8 \\
\hline Neutral & 1 & 5.9 & 2 & 11.8 & - & & 2 & 11.8 & 3 & 17.7 & 1 & 5.9 & 2 & 11.8 & 1 & 5.9 & - & & - & & 2 & 11.8 & 2 & 11.8 \\
\hline Slight Cool & 2 & 11.8 & - & & 1 & 5.9 & - & & 3 & 17.7 & - & & 1 & 5.9 & - & & - & & - & & - & & - & \\
\hline Cool & - & & - & & - & & 1 & 5.9 & 3 & 17.7 & - & & - & & - & & - & & - & & - & & - & \\
\hline Cold & 1 & 5.9 & 2 & 11.8 & 3 & 17.7 & 2 & 11.8 & - & & - & & - & & - & & - & & - & & - & & - & \\
\hline Very Cold & - & & 2 & 11.8 & 3 & 17.7 & 4 & 23.5 & - & & - & & - & & - & & - & & - & & - & & - & \\
\hline Extremely Cold & - & & - & & - & & & & & & - & & - & & - & & - & & - & & - & & - & \\
\hline
\end{tabular}

Table 4: Subjective measurement of thermal comfort

\begin{tabular}{|c|c|c|c|c|c|c|c|c|c|c|c|c|c|c|c|c|c|c|c|c|c|c|c|c|}
\hline & \multicolumn{2}{|c|}{ MAY'13 } & \multicolumn{2}{|c|}{ JUN'13 } & \multicolumn{2}{|c|}{ JUL'13 } & \multicolumn{2}{|c|}{ AUG'13 } & \multicolumn{2}{|c|}{ SEPT'13 } & \multicolumn{2}{|c|}{ OCT'13 } & \multicolumn{2}{|c|}{ NOV'13 } & \multicolumn{2}{|c|}{ DEC'13 } & \multicolumn{2}{|c|}{ JAN'14 } & \multicolumn{2}{|c|}{ FEB'14 } & \multicolumn{2}{|c|}{ MAR'14 } & \multicolumn{2}{|c|}{ APRIL'14 } \\
\hline & $\mathrm{N}$ & $\%$ & $\mathrm{~N}$ & $\%$ & $\mathrm{~N}$ & $\%$ & $\mathrm{~N}$ & $\%$ & $\mathrm{~N}$ & $\%$ & $\mathrm{~N}$ & $\%$ & $\mathrm{~N}$ & $\%$ & $\mathrm{~N}$ & $\%$ & $\mathrm{~N}$ & $\%$ & $\mathrm{~N}$ & $\%$ & $\mathrm{~N}$ & $\%$ & $\mathrm{~N}$ & $\%$ \\
\hline Very Uncomfortable & 12 & 70.6 & 13 & 76.5 & 10 & 58.8 & 10 & 58.8 & 12 & 70.6 & 10 & 58.8 & 3 & 17.7 & 4 & 23.5 & 5 & 29.4 & 4 & 23.5 & 2 & 11.8 & 12 & 70.6 \\
\hline Uncomfortable & 2 & 11.8 & 4 & 23.5 & 6 & 35.3 & 6 & 35.3 & 2 & 11.8 & 4 & 23.5 & $y$ & 52.9 & $T$ & 41.2 & 8 & 47.1 & 7 & 41.2 & 8 & & 2 & 11.8 \\
\hline $\begin{array}{l}\text { Slightly } \\
\text { uncomfortable }\end{array}$ & 2 & 11.8 & - & - & 1 & 5.9 & 1 & 5.9 & 3 & 17.7 & 3 & 17.7 & 3 & 17.7 & 5 & 29.4 & 2 & 11.8 & 3 & 17.7 & 3 & 17.7 & 2 & 11.8 \\
\hline Not comfortable & 1 & 5.9 & - & - & - & - & - & - & - & - & - & - & 2 & 11.8 & - & & 2 & 11.8 & 3 & 17.7 & 4 & 23.5 & 1 & 5.9 \\
\hline
\end{tabular}

Table 5: Subjective measurement of thermal preference

\begin{tabular}{|c|c|c|c|c|c|c|c|c|c|c|c|c|c|c|c|c|c|c|c|c|c|c|c|c|}
\hline & \multicolumn{2}{|c|}{ MAY'13 } & \multicolumn{2}{|c|}{ JUN'13 } & \multicolumn{2}{|c|}{ JUL'13 } & \multicolumn{2}{|c|}{ AUG'13 } & \multicolumn{2}{|c|}{ SEPT'13 } & \multicolumn{2}{|c|}{ OCT'13 } & \multicolumn{2}{|c|}{ NOV'13 } & \multicolumn{2}{|c|}{ DEC'13 } & \multicolumn{2}{|c|}{ JAN'14 } & \multicolumn{2}{|c|}{ FEB'14 } & \multicolumn{2}{|c|}{ MAR'14 } & \multicolumn{2}{|c|}{ APR'14 } \\
\hline & $\mathrm{N}$ & $\%$ & $\mathrm{~N}$ & $\%$ & $\mathrm{~N}$ & $\%$ & $\mathrm{~N}$ & $\%$ & $\mathrm{~N}$ & $\%$ & $\mathrm{~N}$ & $\%$ & $\mathrm{~N}$ & $\%$ & $\mathrm{~N}$ & $\%$ & $\mathrm{~N}$ & $\%$ & $\mathrm{~N}$ & $\%$ & $\mathrm{~N}$ & $\%$ & $\mathrm{~N}$ & $\%$ \\
\hline $\begin{array}{l}\text { Much } \\
\text { warmer }\end{array}$ & - & - & - & - & - & - & 15 & 88.2 & - & - & - & - & 2 & 11.8 & 5 & 29.4 & 4 & 23.5 & - & - & - & - & - & - \\
\hline Warmer & 15 & 88.2 & 14 & 82.3 & 15 & 88.2 & 1 & 5.9 & 13 & 76.5 & 14 & 82.3 & 8 & 47.1 & 8 & 47.1 & 7 & 41.2 & - & - & 3 & 17.7 & 4 & 23.5 \\
\hline $\begin{array}{l}\text { Slight } \\
\text { Warmer }\end{array}$ & 2 & 11.8 & 3 & 17.7 & 2 & 11.8 & 1 & 5.9 & 4 & 23.5 & 3 & 17.7 & 5 & 29.4 & 3 & 17.7 & 3 & 17.7 & 6 & 35.3 & 2 & 11.8 & 2 & 11.8 \\
\hline No change & - & - & - & - & - & - & - & - & 1 & 5.9 & - & - & 2 & 11.8 & 1 & 5.9 & 3 & 17.7 & - & - & 2 & 11.8 & 2 & 11.8 \\
\hline Slight cooler & - & - & - & - & - & - & - & - & - & - & - & - & - & - & - & - & - & - & - & - & - & - & - & - \\
\hline Cooler & - & - & - & - & - & - & - & - & - & - & - & - & - & - & - & - & - & - & - & - & - & - & - & - \\
\hline Much cooler & - & - & - & - & - & - & - & - & - & - & - & - & - & - & - & - & - & - & - & - & - & - & - & - \\
\hline
\end{tabular}

Table 6: Subjective measurement of thermal pleasantness

\begin{tabular}{|c|c|c|c|c|c|c|c|c|c|c|c|c|c|c|c|c|c|c|c|c|c|c|c|c|}
\hline & \multicolumn{2}{|c|}{ MAY'13 } & \multicolumn{2}{|c|}{ JUN'13 } & \multicolumn{2}{|c|}{ JUL'13 } & \multicolumn{2}{|c|}{ AUG'13 } & \multicolumn{2}{|c|}{ SEPT'13 } & \multicolumn{2}{|c|}{ OCT'13 } & \multicolumn{2}{|c|}{ NOV'13 } & \multicolumn{2}{|c|}{ DEC'13 } & \multicolumn{2}{|c|}{ JAN'14 } & \multicolumn{2}{|c|}{ FEB'14 } & \multicolumn{2}{|c|}{ MAR'14 } & \multicolumn{2}{|c|}{ APR'14 } \\
\hline & $\mathrm{N}$ & $\%$ & $\mathrm{~N}$ & $\%$ & $\mathrm{~N}$ & $\%$ & $\mathrm{~N}$ & $\%$ & $\mathrm{~N}$ & $\%$ & $\mathrm{~N}$ & $\%$ & $\mathrm{~N}$ & $\%$ & $\mathrm{~N}$ & $\%$ & $\mathrm{~N}$ & $\%$ & $\mathrm{~N}$ & $\%$ & $\mathrm{~N}$ & $\%$ & $\mathrm{~N}$ & $\%$ \\
\hline Very Pleasant & 12 & 70.6 & 12 & 70.6 & - & - & - & - & - & - & - & - & 3 & 17.7 & 4 & 23.5 & 2 & 11.8 & - & - & - & - & - & - \\
\hline Pleasant & 4 & 23.5 & 2 & 11.8 & - & - & 4 & 23.5 & 6 & 35.3 & 7 & 41.2 & 9 & 52.9 & 9 & 52.9 & 9 & 52.9 & - & - & - & - & - & - \\
\hline Slight pleasant & 3 & 17.7 & 2 & 11.8 & 3 & 17.7 & 5 & 29.4 & 4 & 23.5 & 7 & 41.2 & 5 & 29.4 & 3 & 17.7 & 6 & 35.3 & 2 & 11.8 & - & - & 2 & 11.8 \\
\hline Neither pleasant Nor pleasant & - & & - & & 4 & 23.5 & 1 & 5.9 & 2 & 11.8 & - & - & - & - & - & - & - & - & 3 & 17.7 & 2 & 11.8 & 3 & 17.7 \\
\hline Slight unpleasant & - & & 1 & 5.9 & 1 & 5.9 & 1 & 5.9 & 2 & 11.8 & - & - & - & - & - & - & - & - & 2 & 11.8 & 2 & 11.8 & 2 & 11.8 \\
\hline Unpleasant & - & & - & - & 7 & 52.9 & 6 & 35.3 & 3 & 17.7 & 3 & 17.7 & - & - & - & - & - & - & 7 & 41.2 & 7 & 41.2 & 8 & 47.1 \\
\hline Very unpleasant & - & & - & - & 2 & 11.8 & - & - & - & & - & & - & - & - & - & - & - & 3 & 17.7 & 6 & 35.3 & 2 & 11.8 \\
\hline
\end{tabular}

Table 7: Subjective measurement of thermal acceptability

\begin{tabular}{|c|c|c|c|c|c|c|c|c|c|c|c|c|c|c|c|c|c|c|c|c|c|c|c|c|}
\hline & \multicolumn{2}{|c|}{ MAY'13 } & \multicolumn{2}{|c|}{ JUN'13 } & \multicolumn{2}{|c|}{ JUL'13 } & \multicolumn{2}{|c|}{ AUG'13 } & \multicolumn{2}{|c|}{ SEPT'13 } & \multicolumn{2}{|c|}{ OCT"13 } & \multicolumn{2}{|c|}{ NOV'13 } & \multicolumn{2}{|c|}{ DEC'13 } & \multicolumn{2}{|c|}{ JAN'14 } & \multicolumn{2}{|c|}{ FEB'14 } & \multicolumn{2}{|c|}{ MAR'14 } & \multicolumn{2}{|c|}{ APR'14 } \\
\hline & $\mathrm{N}$ & $\%$ & $\mathrm{~N}$ & $\%$ & $\mathrm{~N}$ & $\%$ & $\mathrm{~N}$ & $\%$ & $\mathrm{~N}$ & $\%$ & $\mathrm{~N}$ & $\%$ & $\mathrm{~N}$ & $\%$ & $\mathrm{~N}$ & $\%$ & $\mathrm{~N}$ & $\%$ & $\mathrm{~N}$ & $\%$ & $\mathrm{~N}$ & $\%$ & $\mathrm{~N}$ & $\%$ \\
\hline Acceptable & 17 & 100 & 13 & 76.5 & 10 & 58.8 & 10 & 58.8 & 8 & 47.1 & 12 & 70.6 & 16 & $\begin{array}{l}94.1 \\
59\end{array}$ & 17 & 100 & 15 & 88.3 & 4 & 23.5 & 2 & 11.7 & 4 & $\begin{array}{l}23.5 \\
765\end{array}$ \\
\hline
\end{tabular}

Table 8: Subjective measurement of thermal satisfaction

\begin{tabular}{|c|c|c|c|c|c|c|c|c|c|c|c|c|c|c|c|c|c|c|c|c|c|c|c|c|}
\hline & \multicolumn{2}{|c|}{ MAY'13 } & \multicolumn{2}{|c|}{ JUN'13 } & \multicolumn{2}{|c|}{ JUL'13 } & \multicolumn{2}{|c|}{ AUG'13 } & \multicolumn{2}{|c|}{ SEPT'13 } & \multicolumn{2}{|c|}{ OCT'13 } & \multicolumn{2}{|c|}{ NOV'13 } & \multicolumn{2}{|c|}{ DEC'13 } & \multicolumn{2}{|c|}{ JAN'14 } & \multicolumn{2}{|c|}{ FEB'14 } & \multicolumn{2}{|c|}{ MAR'14 } & \multicolumn{2}{|c|}{ APR'14 } \\
\hline & $\mathrm{N}$ & $\%$ & $\mathrm{~N}$ & $\%$ & $\mathrm{~N}$ & $\%$ & $\mathrm{~N}$ & $\%$ & $\mathrm{~N}$ & $\%$ & $\mathrm{~N}$ & $\%$ & $\mathrm{~N}$ & $\%$ & $\mathrm{~N}$ & $\%$ & $\mathrm{~N}$ & $\%$ & $\mathrm{~N}$ & $\%$ & $\mathrm{~N}$ & $\%$ & $\mathrm{~N}$ & $\%$ \\
\hline Satisfied & 16 & 94.1 & 13 & 76.5 & 10 & 58.8 & 10 & 58.8 & 10 & 58.8 & 14 & 82.3 & 16 & 94.1 & 17 & 100 & 16 & 94.1 & 6 & 35.3 & 3 & 17.7 & 4 & 23.5 \\
\hline Dissatisfied & 1 & 5.9 & 4 & 23.5 & 7 & 41.2 & 7 & 41.2 & 7 & 41.2 & 3 & 17.7 & 1 & 5.9 & 0 & 0.0 & 1 & 5.9 & 11 & 64.7 & 14 & 82.3 & 13 & 76.5 \\
\hline
\end{tabular}

A subjective questionnaire was completed by interviewing each subject every hour to determine the level of acceptability of the microclimatic conditions during the block laying activity. The ISO extended 11point of the thermal sensation scale was used [14]. Each subject gave ratings of thermal sensation, comfort, preference, pleasantness, acceptance and satisfaction (Tables 3 to 8 ).

\section{DISCUSSION}

The discussion for this study was divided into three areas, namely the subjective, environmental and physiological responses. The contribution of solar load to thermal strain when working in the heat was estimated. The conditions investigated accounted for the time of the day and as well as the weather conditions and the varieties of clothing wore. The 
human physiological and subjective responses were observed with 204 participants in various environmental conditions over 12 months. It is very difficult to determine the constant relationship between the human responses and outdoor climate.

\subsection{Subjective Response}

Two thousand and forty $(2,040)$ questionnaires were administered to 204 masons who participated in the research work. Table 4 showed that in June 2013 that $76.5 \%$ of the mason felt very uncomfortable to the thermal condition. Similarly, Table 7 showed that there was $100 \%$ acceptability of the thermal conditions in May and December 2013. The months of February, March and April 2014 had highest thermal unacceptability of $76.6,88.3$ and $76.3 \%$ respectively. The thermal unacceptability of the masons could affect the performance output which is the subject of the exergy performance and the stored for the mason.

Furthermore, Table 8 also showed that in the months of May and December 2013 most of the participants were satisfactory with the thermal condition of 94.0 and $100 \%$. This table also reflected the unsatisfactory response of the thermal condition in March (82.3\%) and April 2014 (76.6\%).

\subsection{Environmental Response}

Ogun state, Nigeria had a mild weather conditions from May 2013 to April 2014 with lowest mean air temperature, $27.9^{\circ} \mathrm{C}$ recorded in July 2013 while the highest mean air temperature, $36.1^{\circ} \mathrm{C}$ occurs in November 2013 and March 2014 (Table 1). Though, it was a mild weather condition over a year but a person may have cold stress or heat stress. In the month of July 2013, it is possible for any mason to get cold stress due to the type of cloth wore. The relative humidity was not much change around the year. July 2013 showed the highest relative humidity of $69 \%$ and the lowest of $42 \%$ in February 2014 (Table 1). At high humidity levels, too much skin moisture tends to increase discomfort [15], particularly skin moisture that is physiological in origin (water diffusion and perspiration). As a matter of fact, relative humidity affects the evaporation from the skin, which is the prevailing way of heat loss at high air temperatures, normally from $26^{\circ} \mathrm{C}$. At lower relative humidity more sweat is required to evaporate from the body, while at higher values, it is harder for this process to happen, because the air's moisture content is already elevated [16]. Therefore, very humid environments (relative humidity $>70-80 \%$ ) are usually uncomfortable because the air is close to the saturation level, thus strongly reducing the possibility of heat loss through evaporation [17]. On the other hand, very dry environments (relative humidity $<20-30 \%$ ) are also uncomfortable because of their effect on the mucous membranes [17]. At high humidity levels, thermal sensation alone is not a reliable predictor of thermal comfort [18]. The discomfort appears to be due to the feeling of the moisture itself, increased friction between skin and clothing with skin moisture [19]. To prevent warm discomfort, ASHRAE [3] recommended that on the warm side of the comfort zone the relative humidity should not exceed $60 \%$.

The wind speed seems to have a tendency around a year which across the season. The fluctuation between the highest mean wind speed $0.5 \mathrm{~m} / \mathrm{sec}$ and the lowest $0.4 \mathrm{~m} / \mathrm{sec}$ in each month was very minimal and it may be considered that particular tendencies exist. The average mean wind speed throughout the research year was between $0.4 \mathrm{~m} / \mathrm{s}$ and $0.5 \mathrm{~m} / \mathrm{s}$ (Table 1 ).

It was evident that mean average solar radiation was high, 806W/m² in the month of December 2013 and the lowest of $484 \mathrm{~W} / \mathrm{m}^{2}$ in the month of February 2014 due to the revolution and the change of altitude (Table 1). However, the low solar radiations in the different months seem to be influenced by cloud cover rather than the altitude. Air pollution may also have effect on the solar radiation reaching to the ground. The mean average radiant temperature was also at maximum at $36.9^{\circ} \mathrm{C}$ in June 2013 while $29.5^{\circ} \mathrm{C}$ was recorded as the minimum mean radiant temperature in July 2013. This was also by the change in the altitude.

\subsection{Physiological Response}

The aural temperature and sweat loss seemed to have been strongly affected by air temperature. Hence, the mean skin temperature is highly influenced by mean radiant temperature. It was discovered that the highest mean skin temperature for the mason, $34.8^{\circ} \mathrm{C}$ occur in March 2014 while the lowest of $33.1^{\circ} \mathrm{C}$ occurs in May 2013 (Table 2). The aural temperature and evaporative sweat loss were strongly related to the preference and acceptance of the thermal environmental conditions. The skin temperature greater than $45^{\circ} \mathrm{C}$ or less than $18^{\circ} \mathrm{C}$ causes pain [3]. Skin temperatures associated with comfort at sedentary activities are $33^{\circ} \mathrm{C}$ to $34^{\circ} \mathrm{C}$ and decrease with activity [3]

The human skin can absorb radiation and the skin temperature cannot be a major index for thermal comfort under large heat exchange by radiation. Hence, the skin temperature was not correlated with the thermal conditions of the individual. The core temperature showed the highest value of $35.2^{\circ} \mathrm{C}$ in September 2013 and lowest value of $33.1^{\circ} \mathrm{C}$ in February 2014. In contrast to skin temperature, and internal temperature increases with activity. The temperature regulatory center in the brain is about $36.8^{\circ} \mathrm{C}$ at rest in comfort and increases to about $37.4^{\circ} \mathrm{C}$ when walking and $37.9^{\circ} \mathrm{C}$ when jogging [3]. An internal temperature less than about $28^{\circ} \mathrm{C}$ can lead to serious cardiac arrhythmia and death, and a temperature greater than $46^{\circ} \mathrm{C}$ can cause irreversible brain damage [3]. Therefore, the careful regulation of body temperature is critical to comfort and health. However, human responses seems to be influenced by actual outdoor climate condition which consist of solar radiation and wind speed etc and people could have 
different responses due to various internal body temperature or various skin temperature.

\section{CONCLUSION}

Skin temperature seems to be fluctuated by environmental conditions such as solar radiation, air velocity and the set point of skin temperature could be different depending on the season and hot or cold environment.

Therefore developing heat transfer coefficient will be useful for improving human heat balance equation for outdoor condition. The questionnaire could also be developed not with direct question but with question for their actual psychological and subjective symptom which can correspond with actual human physiological responses. Future research should be conducted and considered in a wider range of environmental conditions. Furthermore, the exposure time could be considered for human responses and their strain during outdoor activity and figure out the maximum exposure time depending on environment condition would also be very important. So, more data collection would also be needed for quantifying human responses to outdoor thermal condition.

\section{REFERENCES}

[1]Bulcao CF, Frank SM, Raja SN, Tran KM, Goldstein DS, "Relative contribution of core and skin temperatures to thermal comfort in humans". J Therm Biol 25(1-2):147-150, 2000.

[2]Yao Y, Lian Z, Liu W, Shen Q, "Experimental study on skin temperature and thermal comfort of the human body in a recumbent posture under uniform thermal environments". Indoor Built Environ 16(6):505, 2007.

[3]ASHRAE "Physiological principles and thermal comfort". ASHRAE handbook of fundamentals (Chapter 8 ed., pp. 8.1-8.28). 2001, Atlanta, USA

[4]Fanger P.O. "Thermal comfort - Analysis and application in Environmental Engineering". Danish Technical Press, Copenhagen, 1970.

[5]Fanger P.0, "Thermal comfort". McGraw-Hill, New York, 1972.

[6]Maw G, Boutcher S, Taylor N, "Ratings of perceived exertion and effect in hot and cool Environments". Eur J Appl Phys 67:174-179, 1993.

[7]Sparks S, Cable N, Doran D, Maclaren D, "The influence of environmental temperature on duathlon performance". Ergonomics 48:15581567, 2005.

[8] Kenny NA, Warland JS, Brown RD, Gillespie TJ "Part B: Revisions to the COMFA outdoor thermal comfort model for application to subjects performing physical activity". Int J Biometeorology 53:429-441, 2009.

[9] Nikolopoulou, M., Baker, N., \& Steemers, K. "Thermal comfort in outdoor urban spaces: understanding the human parameter". Solar Energy, 70(3), 227-235, 2001.

[10] Thorsson S, Honjo T, Lindberg F, Eliasson I, Lim EM., "Thermal comfort and outdoor activity in japanese urban public places". Environ Behav 39(5):660-684, 2007.

[11] Parsons KC, "Human thermal environments: the effects of hot, moderate and cold environments on human health, comfort and performance". 2nd edn. Taylor and Francis, New York, 2003

[12] SPSS Version 17, www.spss.software. informer.com

[13] Microsoft Excel (2010), Microsoft office system files applications, www.microsoft.com

[14] IS010551 (2001). Ergonomics of the thermal environment - assessment of the influence of the thermal environment using subjective judgment scales. Geneva: the International Organization for Standardization, 2001.

[15] Berglund, L.G. "Comfort criteria: Humidity and standards. Proceedings of Pan Pacific Symposium on Building and Urban EnvironmentalConditioning in Asia 2:369-82, 1995. Architecture Department, University of Nagoya, Japan

[16] La Roche, P. “Carbon-neutral architectural design”, CRC Press, 2011

[17] Wolkoff, S. K.; Kjaergaard. "The dichotomy of relative humidity on indoor air quality" Environment International 33 (6): 850, 2007.

[18] Tanabe S, Kobayashi K, Nakano J, Ozeki Y, Konishi M. A. "Comprehensive combined analysis with multi-node thermoregulation model (65 $\mathrm{mn})$, radiation model and CFD for evaluation of thermal comfort". Energy Buildings, 34(6):637-46, 2002.

[19] Gwosdow, A.R., J.C. Stevens, L. Berglund, and J.A.J. Stolwijk. "Skin friction and fabric sensations in neutral and warm environments" Textile Research Journal 56:574-80, 1986. 